\title{
Effect of Dress Code of Sri Lankan Female School Teachers on their Job Performance
}

\section{U.G.L.B. Jayasooriya}

University of Peradeniya, Sri Lanka

\section{Saliya De Silva}

Saga University, Japan

\section{W.A.D.P. Wanigasundera}

University of Peradeniya, Sri Lanka

\section{Abstract}

The study examined how clothing of Sri Lankan female school teachers affects their job performances. A representative sample was selected among school teachers from Western and Central provinces. A Sequential Explanatory design integrating quantitative survey $(n=100)$ along with qualitative interviews $(n=15)$ and secondary data were used. Results revealed that evolution and current practices of female dress were more into promote nationalism/culture. Though the current dresses of Sri Lankan school teachers are the Saree (for Sinhalese and Tamil teachers) and Abaya (for Muslim teachers), the majority of the respondents preferred to wear casual dresses (54\%). Wilcoxon Signed Rank test showed significant differences in terms of perceived comfort and performing given four tasks (washing, ironing, dressing and walking after dressed) in favour of casual dress over traditional dress. Thirty percent of respondents have faced accidents due to their current dress. Aforementioned suggested that, teaching and performing extra-curricular activities would be more productive if they wear casual dresses.

\section{Key words:}

Dress Code, Job performance, Females, School teachers 


\section{Introduction}

\section{Clothing and its Relevance to the Work Environment}

Clothing plays a pivotal role in any society as a messenger of fashions and trends as well as an indicator that reflects one's personality, culture, subcultures, religions, occupations and moral values (Wickramarachchi, 2003; Schliesinger, 2014; Bhui et al., 2008). Clothing is one of the critically important basic physiological needs of civilized human beings (Huitt, 2004). Clothing also serves communication and socio psychological functions (Imo, 2013). The subject area of clothing or attire influences many fields such as Sociology, Anthropology, Art, History, Cultural studies, Design studies, Economics, Literature, Semiotics, Visual culture, and Business studies (Melchior \& Skov, 2008). Clothing is also an important concern in the work environment. According to Kenneth and Singh (2014), organizations have dress codes due to four reasons: to promote unity and cohesion, to project a certain attitude or culture, to discourage the formation of subgroups, and to ensure safety, particularly in industry and manufacturing. The literature shows psychological, sociological, economic and safety implications of the dress at work. Considerable number of research conducted worldwide has revealed that the dress of an employee has a relationship with his or her job performance and related attributes (Rosenfeld \& Plax, 1977; McPherson, 1997; Slepian, 2015; Sampson, 2016; Hughes, 2002: Nath et al., 2016; Franz \& Norton, 2001). Non-verbal communication, personality, quality of work, formality and efficiency can be recognized as attributes that contribute to determine performance at work. Attire has been identified as an important aspect of nonverbal behavior and communication (Rosenfeld \& Plax, 1977; Sampson, 2016; Hughes, 2002). Since non-verbal and verbal communications include individual's values, attitudes, interests, lifestyle, social and personal relationships and personality (Sampson, 2016; Hughes, 2002), it is clear that dress of an employee is critical in building communication links in a professional environment. Some studies have shown that formal clothing influence negatively to the communication process between people while casual dresses eliminate natural communication barriers (Nath et al., 2016; Franz \& Norton, 2001).

Furthermore, approachability and familiarity have found to be linked with casual clothing whereas social distance, authority and status are linked with formal clothing (Slepian, 2015; Furnham et al., 2014). Employee morale and quality of work has shown improvements as dress codes become more casual (Sharkey, 2000). Hence, the formality or informality of a dress code is a decisive factor that 
affects satisfaction (McPherson, 1997). Studies on dress codes of doctors, nurses, teachers and lawyers have shown relationship between suitability of attire and productivity and effectiveness at work (Kaser et al, 2009; Gutierrez \&Freese, 1999). Dress-down policies or adopting dress codes that are more casual are meant to increase worker productivity, provide cost savings to employees, and improve work quality (Sharkey, 2000). Nevertheless, in contrast some studies have stated that if employees are dressed casually, they may perceive themselves as being in a casual, relaxed, and "laid-back" atmosphere and continually relaxed dress leads to relaxed manners, and relaxed morals (Singh \& Kenneth, 2014: Franz \& Norton, 2001).

Deciding a dress code itself is economic as it involves cost of the dress, weight, material, the style and how the dress is worn which affect the comfort of the wearer. Nickson et al. (2005), have revealed that clothing practices could have material consequences for individuals in terms of either helping or hindering their employability. This shows that dress is a decisive factor as it affects the comfort at workplace. Since the dress affects the physical and psychological comfort at workplace this can also be discussed under Ergonomics. According to Bishop et al. (2013) weight and bulk of the clothing, visual and tactile reductions associated with some clothing, and the heat stress in hot ambient environments are main considerations in deciding an employee friendly dress. Hence, improving the comfort of the dress found to be a move towards enhancing human performance and productivity at work. Cost is another crucial determinant in deciding a dress code. Employees tend to save money when they wear casual dresses for work because casual business wear is generally less expensive and requires less professional care than traditional business attire (McPherson, 1997). Time is also a factor that affects productivity. If the dress is considered, time taken for dressing and time taken to perform particular duties wearing a dress are main concerns. Referring to dress codes, Gentile and Imberman (2010) have stated that some people take hours to dress, while in case of a uniform it would take only three minutes. This shows that a dress which is easy to wear and easy to handle is both employee and employer friendly. Dress can also make the wearer vulnerable to risks. Complex and lengthy dresses such as Sarees and Shalwas are found to be vulnerable to risks and accidents (Kumar et al., 2006; Yadav et al., 2016; Gupta et al., 2016). 


\section{Sri Lankan Female School Teachers' Dress}

Sri Lanka is a multi-ethnic and multi-religious South Asian country with a population of 21.7 million. In 2017, there were 4,165,964 students in 10,194 schools island wide (Ministry of Education, 2017). There is a total of 241,591 teachers and majority (73\%) of them are females (Ministry of Education, 2018).

The females of Sri Lanka follow global clothing patterns as well as traditional clothing patterns. Saree (Figure 1) is one of the famous and commonly used dresses among Sri Lankan females. Saree is worn in different styles: Indian style mainly in the low country (peripheral part of the country) and Osari in the up country (Central part of the country) of Sri Lanka. The difference between Osari and Saree remains not in the garment but in style it is worn. Osari is considered to be more of Sri Lankan origin (hereafter, both these styles will be referred to as Saree). Saree is a dress worn with a material of six yards (5.5 meters) that has to be draped around the body with a fall, a jacket, an underskirt and few safety pins ranging from 5 to 20. Pins are used to keep the pleats neat and attach Saree to the jacket and the underskirt. The number of pleats and the pins may vary on the person.

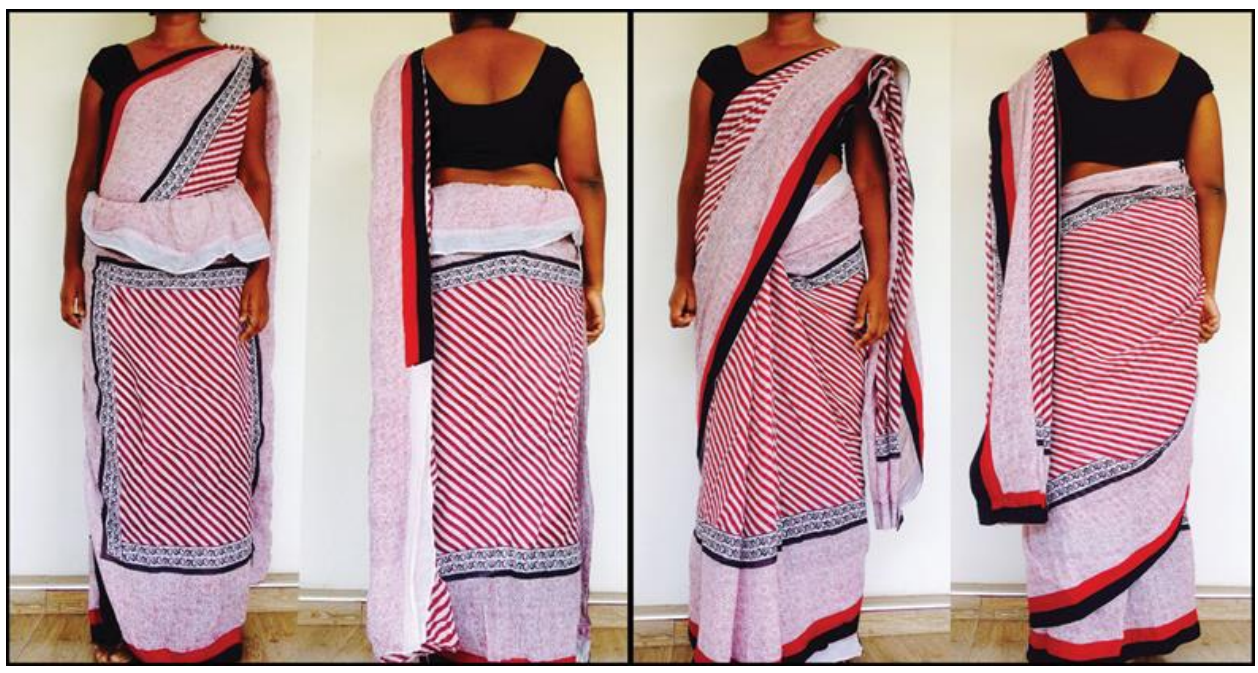

Figure 1: A woman in Osari (left) and Saree (right)

Saree is considered to be the nationally accepted, traditional and cultural dress for the majority of the females in Sri Lanka (Jayasooriya et al., 2020). It is also the commonly worn and most popular official dress for Sri Lankan women in almost 
all the government organizations as well as in some private companies. It is also recognized as a formal dress for special occasions. All the female government school teachers in Sri Lanka wear Saree to school except some Muslim teachers, who wear Abaya (which is considered as a dress that conforms to their religion). Almost all female teachers from private schools wear Saree at school. The female school teachers are not obliged by law to wear a Saree as the Circular number 2012/37 (Ministry of Education, 2012) on female school teachers' code of conduct and common law recommends a decent and culturally conform dress ["winitha (decent) ha sanwara bawaya rakenaparidi (well-disciplined) sanskruthiyata anukulau, (culturally conform) pirisidu,(clean) charm(charm) mana piliwelata sakasu (properly arranged) adumakin sarasenna'] at the workplace. Hence, wearing Saree to schools is more like a social norm. This conformity to social norms related to the dress can be driven by a desire to gain social acceptance and status (Cialdini \& Goldstein, 2004) and to avoid negative sanctions such as social disapproval, ridicule, and exclusion (Kruglanski \& Webster, 1991). Willingness to conform is caused as people recognize that even small departures from the social norms will seriously impair their status (Bernheim, 1994). It is also said that in professional and nonprofessional settings, individuals often put a significant effort to learn and adhere to dress codes (Bellezza et al., 2013). Hence, the willingness of Sri Lankan female school teachers to wear Saree over other dresses can be explained through the theory of conformity (Thinada \& Rujirutana, 2008).

\section{Teachers' Role in Schools}

Sri Lankan students have 13 years of compulsory education. The students have to be in the primary classes for 5 years, secondary classes for 6 years and advanced level classes for 2 years. Schools in Sri Lanka start at 7.30 am and finish at 1.30 $\mathrm{pm}$. Duration of one period is 40 minutes to 45 minutes above primary level and 30 minutes for primary level.

There are nearly 8 periods per day; 4 or 5 periods before the lunch break and 3 periods after the lunch break. Lunch break lasts 15 minutes. Both teachers and students have no breaks/recess in between the periods or after the lunch break. Students may have after school activities; sport activities, activities of different societies and associations which are not made compulsory. Sports activities can be compulsory depending on the school. Teachers stay afterschool as teachers-in -charge of such extra-curricular activities but not all the teachers are engaged in 
such. Apart from the sports activities, teachers conduct after school classes for students whose examinations are nearby. Nevertheless, this duty assigned to teachers may or may not be compulsory, this is left to the discretion of schools. Teachers are not necessarily supposed to attend schools during the vacation unless there are some pre decided arrangements and duties.

\section{Significance of the study}

Students are the cream of the society. Teachers, as the personnel who is responsible in educating students, have to play an important role in the society. Teachers' efficiency, effectiveness and satisfaction at work is important and those can directly or indirectly affect students. As per the prior researches, the dress that teachers wear at school can affect non-verbal behavior and communication (Rosenfeld \& Plax, 1977; Sampson, 2016; Hughes, 2002), approachability and familiarity (Slepian, 2015; Furnham et al., 2014), morale and quality at work (Sharkey, 2000), satisfaction (McPherson, 1997), productivity and effectiveness at work (Kaser et al, 2009; Gutierrez \&Freese, 1999), work quality (Sharkey, 2000), comfort (Nickson et al., 2005), savings (McPherson, 1997; Sharkey, 2000 ), time taken to get ready (Gentile \& Imberman 2010), and vulnerability to risks and accidents (Kumar et al., 2006; Yadav et al., 2016; Gupta et al., 2016). Hence, the job performance, effectiveness and the efficiency of the duties that teachers perform are likely to be affected by their dress as the prior researches have proved psychological, sociological, economic and safety implications of the dress. Nevertheless, there is hardly any research based on Sri Lanka to find out how dress affects job performances. Therefore, the impact of Sri Lankan female school teachers' dress on their job performance needs investigation to bridge this existing knowledge gap. Hence, the current study was conducted to determine the impact of official dress code on job performance of female school teachers in Sri Lanka. This broader objective was achieved through three specific objectives: 1 . finding out the factors that determine the official dress code of female schoolteachers, 2. determining sociological, psychological, economic and safety outcomes of an official dress and 3. investigating implications of a dress on job performance of the wearer. 


\section{Theoretical background}

\section{Views of dress code from symbolic internationalist perspective}

Symbolic interaction has been described as the study of social actions and social objects (McCall \& Simmons, 1996). Social actions are actions and reactions related to individuals that consider the behavior of others ("Social actions", 2020). A symbolic interactionist approach places more emphasis on the role of dress in social communication, with consideration for both wearers' and perceivers' viewpoints (Kaiser, 1983).

Dress can be considered as a material thing that affects the appearance of individuals so do the actions and reactions among individuals. Cultural definitions about appearance plays an important role in the communication process (Jackson $\&$ 1994). Alicke et al. (1986) have noted that appearance and body can serve as a vehicle for the communication of non-verbal messages. Moreover, they have explained that culture plays a prominent role in this process as these messages are organized in culturally derived signs and symbols that are used to assign meaning to appearance and symbolically communicated by the individuals' appearance. Accordingly, as the dress of individuals greatly affects their appearance, that also affects the symbolic messages they communicate with others non-verbally. Therefore, dress plays a major role in adding symbolic meaning to the messages they communicate. This is evident in the context of Sri Lanka as the cultural value ascribed to the dress Saree is prevalent and dominant. Since, Saree has been a dress that women used to wear from the past and evolved as the most suitable dress to promote nationalism, act of wearing Saree symbolizes nationalism and cultural conformity.

According to Kaiser (1983), a number of social variables are defined in certain contexts by dress: 1. Degree of formality, (e.g., an appropriate dress for a dinner party); 2. Identities of, and relationships between, participants (e.g., power or status differences); 3. Degree of familiarity with a situation, i.e., how unique or unfamiliar a situation is to a person; 4. Salience of a situation, or the degree of regard that individuals hold for it (e.g., the attire in a job interview); 5. Possibilities for overt actions such as physical activities. These cultural definitions about appearance plays an important role in the process of communication (Jackson \& 1994). For example while Saree is the ideal and most desired dress to be worn for a job interviews in the Sri Lankan context, it is completely different for other cultural contexts as people in the society understand and interpret social actions 
based on symbolic meanings that culture has assigned to them. Moreover, clothes serve two functions in the course of social actions and interactions with regard to communication: the negotiation of identities and the definition of situations (Kaiser, 1983). This provides insight to understand, establishment of Saree as a dress norm for the female school teachers in Sri Lanka as Saree tends to symbolize the identity of teachers. In addition, female teachers wearing Saree has become a sign of a school setting in Sri Lanka.

\section{Self-concept/image and social identity construction at work place}

Cognitive theorists regard clothes as cues that may be selected by perceivers to understand others (Kaiser, 1983). Self- concept is one of the important concepts among cognitive theorists. Self- concept is one's own definition and evaluation of oneself, which contributes to the individual sense of identity (American Psychological Association, n.d.). Hence, self-concept affects to how a person presents oneself to others. Roach-Higgins \& Ellen (1995) suggest that appearance refers to visual presentation of self. Dress is an integral and one of the most influential parts of appearance. Therefore, it is clear that dress affects the way how individuals present themselves to the society. This self-presentation creates certain impressions about oneself in others. Self can also be defined as a composite of an individual's identities communicated by dress, bodily aspect of appearance, as well as the meanings assigned to situations (Roach-Higgins \& Ellen, 1995).

Nevertheless, Hunt \& Miller (1997) state that, prevailing dress and appearance norms are ambivalent and ambiguous which result in making any dress and appearance action "conforming" or "deviant". Accordingly, dress can assist presenting oneself in a manner that society accepts or rejects creating either positive or negative impressions. Likewise, dress as a part of the personality of a person can affect interactions between coworkers and customers. Moreover, dress is able to establish an identity of a person before the conversation can be initiated (Roach-Higgins \& Ellen, 1995). Affirming this idea, it has been found that formal clothing establishes social distance, authority and status while casual clothing establishes approachability and familiarity (Slepian, 2015; Furnham et al., 2014). Hence, it is clear that clothing can be used successfully to attribute certain qualities to oneself, before verbal communication or interactions. Similarly, dress confers identities on individuals as it communicates positions within structures (RoachHiggins \& Ellen, 1995). This way, dress can be used to distinguish between different hierarchical positions in an organization and to create good first impressions in customers at work place. 
Moreover, dress can be considered as an important aspect of different types of schemas prevailing in a society. Role schemas which describes our expectations on how a person in a specific role should behave is a fine example (Vinney, 2019). Similarly, Sri Lankan society consists of role schemas about female school teachers in which Saree is included. We also have social schemas and event schemas on how to behave in different social situations and events (Vinney, 2019). An instance where social schemas and event schemas are attached with the dress Saree is some principals of schools wanting female guardians/mothers of students to wear Saree when visiting to school (Zoysa, 2015).

\section{Methodology}

The study was conducted in Sri Lanka. Ethical clearance for the study was obtained from the Ethical Review Committee, Faculty of Medicine, University of Peradeniya under the protocol No 2019/EC/04. A Sequential Explanatory Design (QUANT->qual) was used for the study. Integrating both qualitative and quantitative approaches was found to be successful in obtaining in-depth understanding about the information derived from the quantitative data. Acrosssectional sample study was employed for the study, while in terms of using secondary data longitudinal studies were also incorporated. Quantitative data were collected by a self-administrated questionnaire, while face to face interviews and telephone interviews were conducted to collect qualitative data. The study population was female school teachers in Sri Lanka. The total number of schools in Sri Lanka is 10,194 (Ministry of Education, 2017). They have been categorized into many types depending on different criteria, such as: private and government schools, provincial and national schools, mixed, girls and boys schools and $1 \mathrm{AB}$ (schools with Science A/L classes and non-science A/L classes), 1C (schools with non-science $\mathrm{A} / \mathrm{L}$ classes), Type 2 (schools with year 1 to year 11 classes only), and type 3(schools with year 1 to 8 or 1 to 5 classes only) (Ministry of Education, 2017).

Schools from Western and Central provinces were selected for the study among 9 provinces in Sri Lanka, having identified these as two major provinces with a good deal of diversity. Western province and Central province were identified as culturally and economically diverse provinces with considerable climatic, socio economic and cultural heterogeneity. The total number of schools in Western province is 1359 while the total number of schools in Central province is 1519 (Ministry of Education, 2017). Ten schools each were selected using purposive sampling from Western and Central provinces, covering at least one school from the above-mentioned categories of schools. 
The number of female school teachers in Sri Lanka is 176,956 and the number of teachers teaching in Western (23\%) and Central (19\%) provinces are higher than that of other provinces. (Ministry of Education, 2017). Considering the time, money and geographical constraints $0.2 \%$ of the population was included in the sample. Accordingly, 160 respondents were targeted. Ten self-administrated questionnaires, enclosing self-addressed stamped envelopes were sent to 10 randomly selected teachers from a given list of names in selected schools after obtaining permission from relevant authorities (total of 200 questionnaires for both provinces). One hundred and ten filled questionnaires out of 200 questionnaires were returned (55\%). Accordingly, 100 participants were considered $(0.13 \%$ of the population) to the sample excluding 10 whose responses were incomplete. The sample consisted of 90 government school teachers and 10 private school teachers. As per the saturation principle, most of the novel information in a qualitative dataset is generated early in the process (Guest et al., 2020). Hence, it was decided that fewer than 16 interviews would be enough for data saturation as used in previous studies (Guest et al., 2020). Accordingly, qualitative interviews were conducted with 15 participants inclusive of interviews with school principals, InService Advisors (ISAs), education and subject directors. The informed written consent was obtained from all the interviewees prior to the study.

They were informed that they could withdraw from the study at any point without giving a reason, the quotes would be used anonymously and they could remain silent if they do not wish to answer. A semi structured questionnaire was used as a guide for the in-depth interviews. Interviewees' perceptions about the dress, their expectations and experiences about dress at work place, their perceptions on how dress affects job performances, and their suggestions for an ideal dress at work place were inquired. The duration of every interview was one hour per participant and all the interviews were transcribed.

The self-administrative questionnaire consisted of questions split under 14 sub topics. Dimensions, variables and the measurements were decided and designed based on prior researches adopting operational definitions: satisfaction/motivation (McPherson, 1997), attractiveness (Sampson, 2016; Hughes, 2002), personal preference (McPherson, 1997), exposure of body (Jayasooriya, 2016), communication (Nath et al, 2016 ; Rosenfeld \& Plax, 1977), formality (Slepian, 2015), social distance (Slepian, 2015), pressure to conform (Thinada \& Rujirutana, 2008), professionalism (Slepian, 2015), time (Gentile \& Imberman, 2010), comfort (McPherson, 1997), Risk of injuries/accidents (Kumar et al., 2006; Yadav et al., 
2016; Gupta et al., 2016). Demographic details and information on working conditions and the career were derived from the first 4 sub topics.

The other sub sections were : Information about financial status, preferences about dresses, perceived comfort of casual and traditional dresses, awareness about dress related rules and norms, attitudes and perceptions about dresses, ability to communicate through the dress, external influence in deciding what to wear, perceived efficiency of casual and traditional dress in terms of time taken to perform given tasks, efficiency and effectiveness of teaching and performing extracurricular activities wearing casual and traditional dress, vulnerability to risk of traditional and casual dresses, satisfaction about the dress and the job, and perceptions of how dress affect to job performances were included in the questionnaire. The answers for questionnaires were derived in five-point scales, as binary answers, as Multiple Choice Questions (MCQs) and also as short answers. Quantitative data were analyzed by using SPSS software. Narrative analysis and thematic analysis were used to analyze qualitative data identifying themes, codes and individual stories to bring about an in-depth understanding of the findings derived from quantitative data.

\section{Results}

\section{Evolution of the Dress of Female School Teachers' in Sri Lanka}

Evolution of Sri Lankan female clothing traces back to many years. History shows that, women who lived in ancient periods wore limited clothing, especially to the upper part of the body (Wickramasinghe, 1935; Hewavissenti, 2014; Wickramasinghe, 2013). Sri Lankan women have also worn western dresses such as gowns during and after colonized era (Jayawardena, 2002).

Though the turning point of Sri Lankan women starting to wear Sarees as a common dress is ambiguous, the literature shows that it was the period of Anagarika Dharmapala, who emphasized the Indian Saree as a suitable garment for Sinhala women, as it covered their black legs, navel and midriff (Jayawardena \& De Alwis1996; Jayawardena, 2002). Women wearing Saree and men wearing Sarong are also considered to be a requirement of national movements as they were said to be symbols of nationalism (Fernando, 2007). Since then until now, Saree has been given due respect, recognition and acceptance in the society and has been used as the most common official dress for women working in many government and private organizations, including schools (Jayasooriya et al., 2020). Figure 2 
shows a teacher wearing Saree (in Osariya style) engaged in teaching in a classroom.

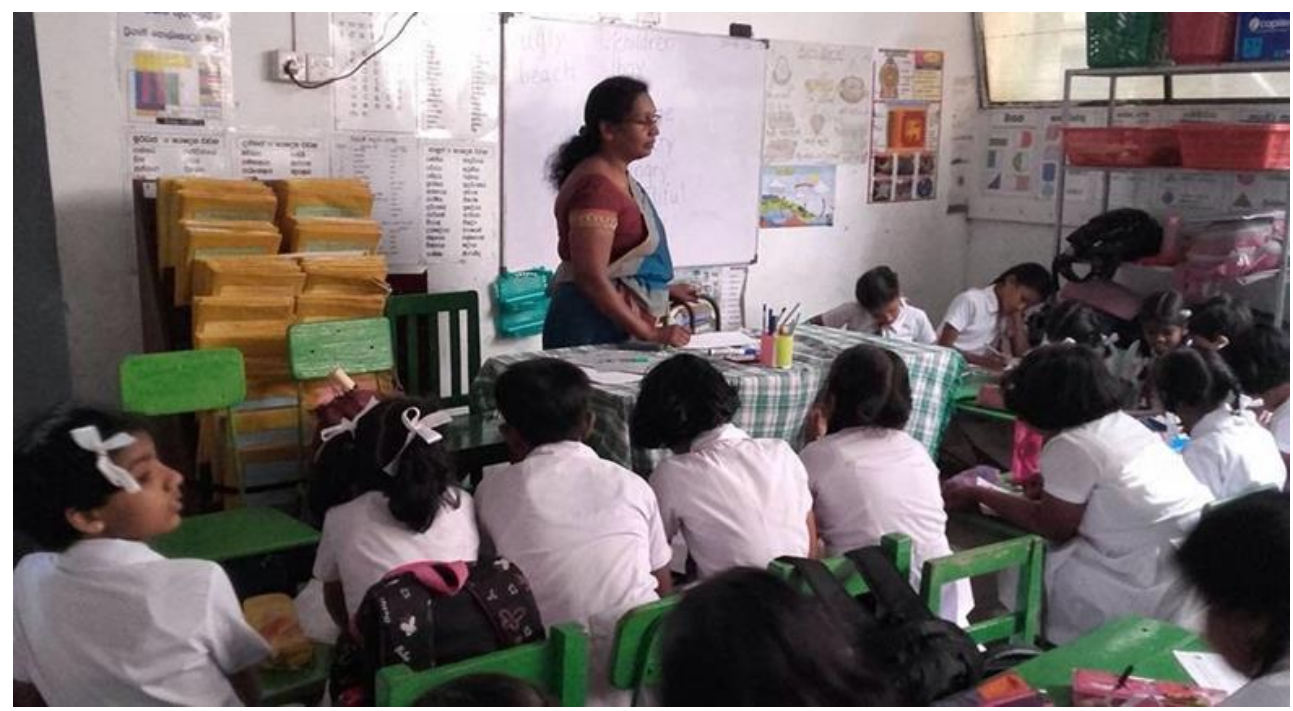

Figure 2: A teacher teaching in a classroom wearing a Saree

\section{Socioeconomic and demographic characteristics of the respondents}

Majority of the respondents were Sinhala Buddhists (94\%). The age of the respondents ranged from 20 years to 65 years (mean= 38years). Work experiences of the respondents ranged from 6 months to 38 years (mean=13 years). Majority in the sample teachers had basic level qualification, which was General Certificate in Education - Advanced Level (82\%). They also had tertiary education including bachelor's degree (55\%), diploma (47\%) or postgraduate degree $(31 \%)$. Accordingly, some teachers had many qualifications, while others had few or one from the given choices. Majority were from government schools (90\%) while the rest was from private sector. The subjects taught varied and there was a wide diversity among subjects. There were higher percentages of teachers who teach English (20\%), Sinhalese (15\%), Science (12\%) and Mathematics (9\%). Additionally, the sample also covered teachers teaching Agriculture, Health and Physical Education, Geography, Civics, Dancing, Tamil, Buddhism, Information Technology, Commerce, Home Science, Logic, Practical and Technical Skills, History and the primary subjects. The average monthly salary of a sample teacher was 213.45 USD (1USD= 186.68 Sri Lankan Rupees) which ranged from 53.57 USD to 455.32 USD. The average amount of savings was 39.32 USD per month which ranged from 1.07 USD to 107.14 USD. The average cost of a dress worn at 
school (Saree) was 32.48 USD that ranged from 2.68 USD to 187.49 USD. Buses were the most popular mode of transport $(65 \%)$.

\section{Socio psychological aspects of the dress}

Current dress of all the respondents were either Saree $(97 \%)$ or Abaya $(3 \%)$. Respondents' preferred dresses were casual dresses (54\%), Saree (34\%), and Abaya (3\%). Respondents were given eight situations to rank perceived comfort in a Likert scale when they are in Saree and casual dresses (See table 1).

Table 1: Perceived comfort of Saree and casual dress

\begin{tabular}{|c|c|c|c|c|}
\hline \multirow[t]{2}{*}{ Situation } & \multicolumn{2}{|c|}{ Casual dress } & \multicolumn{2}{|c|}{ Saree } \\
\hline & $\begin{array}{l}\text { Mean } \\
\text { value }\end{array}$ & $\begin{array}{l}\text { Standard } \\
\text { Deviation }\end{array}$ & $\begin{array}{l}\text { Mean } \\
\text { value }\end{array}$ & $\begin{array}{l}\text { Standard } \\
\text { Deviation }\end{array}$ \\
\hline During sunny/ hot days & 4.00 & 1.03 & 2.33 & 1.02 \\
\hline During rainy/cold days & 4.11 & 1.07 & 1.97 & 1.10 \\
\hline During pregnancy & 4.36 & 0.95 & 1.74 & 1.13 \\
\hline During sports meets & 4.31 & 1.07 & 2.13 & 1.3 \\
\hline $\begin{array}{l}\text { During special events Eg:- } \\
\text { school prize giving }\end{array}$ & 3.37 & 1.41 & 3.11 & 1.34 \\
\hline During school trips & 4.36 & 0.99 & 2.06 & 1.18 \\
\hline $\begin{array}{l}\text { While doing physical } \\
\text { activities including walking }\end{array}$ & 4.37 & 0.97 & 1.87 & 1.06 \\
\hline Weekend events & 4.41 & 0.9 & 2.12 & 1.16 \\
\hline In general & 4.41 & 0.89 & 2.26 & 1.16 \\
\hline
\end{tabular}

Likert Scale: - 1-Highly uncomfortable, 3-moderate, 5- highly comfortable

Mean values depict the perceived level of comfort wearing each dress in the given situations. Wilcoxon signed rank test was performed to find out if the differences of responses referring to two different dresses, were significant or not. The results of the test showed that the perceived comfort of casual dress was significantly $(\mathrm{p}<.005)$ higher than the Saree. Moreover, perceptions about formality and the awareness were measured using the questionnaire. Seven statements were given to rank the level of agreement of the respondents in a five-point Likert scale (see table 2). The majority of participants believed that Saree is a dress that promotes professionalism. 
Table 2: Perceived formality and awareness

\begin{tabular}{|c|c|c|}
\hline Statement & $\begin{array}{l}\text { Mean } \\
\text { value }\end{array}$ & $\begin{array}{l}\text { Standard } \\
\text { deviation }\end{array}$ \\
\hline I am abided by law to wear the dress I wear to school & 3.46 & 0.93 \\
\hline The dress I wear to school is pleasant to others & 3.97 & 0.7 \\
\hline The dress I wear to school is physically attractive & 3.68 & 0.83 \\
\hline $\begin{array}{l}\text { I believe that I look professional when I am in Saree } \\
\text { (compared to any other dress). }\end{array}$ & 4.05 & 0.8 \\
\hline I think it is important to look professional at school & 4.08 & 0.86 \\
\hline $\begin{array}{l}\text { I look formal when I am in Saree (Compared to any } \\
\text { other dress). }\end{array}$ & 3.79 & 0.94 \\
\hline $\begin{array}{l}\text { When I am in Saree students are reluctant to approach } \\
\text { me for guidance and advice }\end{array}$ & 2.02 & 0.82 \\
\hline $\begin{array}{l}\text { Dress I wear at school is a barrier to communicate with } \\
\text { students }\end{array}$ & 2.31 & 0.9 \\
\hline I can show-off from the dress I wear at school & 2.28 & 0.93 \\
\hline
\end{tabular}

Likert Scale: 1-strongly disagree, 2-disagree, 3-Neutral, 4- agree, and 5-strongly agree

Furthermore, they were asked if the dress they wear to work exposes their body. They were asked to rank their responses in a five-point scale (1-yes, 2- yes to a certain extent, 3- yes, sometimes, 4- no, 5- not at all). The mean value was 2.92, indicating that the body is exposed in certain situations. They were also asked to rank their level of comfort when the dress they wear exposes the body (Likert scale; 1 - very uncomfortable and 5- very comfortable). Mean value was 2.28 which indicates that it is uncomfortable.

Ability to communicate through the dress too was assessed by the questionnaire. Respondents were given 8 situations to rank their perceptions in a five-point Likert scale (see table 3). The results showed that the majority of the respondents of the study believed that Saree helps to show that they are teachers $(68 \%)$, but they were not in favour of the idea that the dress expresses authority (mean=2.95). 
Table 3: Descriptive statistics on perceived ability to communicate

\begin{tabular}{clcc}
\hline & \multicolumn{1}{c}{ Statement } & Mean value & $\begin{array}{c}\text { Standard } \\
\text { deviation }\end{array}$ \\
\hline 1. & Express yourself as a teacher & 4.00 & 0.88 \\
2. & Maintain social status & 3.68 & 0.91 \\
3. & Show that you are trustworthy & 3.43 & 1.02 \\
4. & Show your seriousness & 3.06 & 1.10 \\
5. & Express your authority & 2.95 & 1.12 \\
6. & Express nationalism & 3.64 & 1.20 \\
7. & Get social acceptance and recognition & 3.66 & 0.96 \\
8. & Maintain distance between you and your & 3.51 & 0.95 \\
& students & & \\
\hline
\end{tabular}

Likert scale: 1-very high, 2- high, 3-moderate, 4-low, and 5-very low

It was important to find out if the women are influenced by external parties rather than their own preferences in deciding what to wear. Accordingly, the respondents ranked the level of external influences from five given parties: Teachers and friends, family members and relatives, school administration, school community and general public. (Likert scale: 1- very low and 5- very high). The mean values for all five parties were close to 3 , which implied that the influence from all the suggested parties were moderate. Furthermore, respondents were asked to rank the time they take to perform the given four types of tasks in a five-point Likert scale for both Saree and casual dress separately. Mean comparison of the statistics showed that the time taken to perform given tasks is higher when they are in Saree compared to casual dresses (table 4). Wilcoxon Signed Rank test was performed to check whether the responses received for each dress at each situation were significant or not. Test statistics showed that the responses in all four situations were significant $(\mathrm{p}<0.05)$ : significantly more time was required to perform tasks wearing Saree compared to casual dresses.

Table 4: Perceived efficiency in terms of time

\begin{tabular}{lcccc}
\hline \multicolumn{1}{c}{ Description } & \multicolumn{2}{c}{ Casual dress } & \multicolumn{2}{c}{ Saree } \\
& $\begin{array}{c}\text { Mean } \\
\text { value }\end{array}$ & $\begin{array}{c}\text { Standard } \\
\text { deviation }\end{array}$ & $\begin{array}{c}\text { Mean } \\
\text { value }\end{array}$ & $\begin{array}{c}\text { Standard } \\
\text { deviation }\end{array}$ \\
\hline Time taken for ironing & 3.84 & 1.03 & 2.30 & 1.21 \\
Time taken for washing & 3.84 & 1.02 & 2.27 & 1.14 \\
Time taken for getting dressed & 3.74 & 1.22 & 2.78 & 1.24 \\
Time taken for walking & 3.84 & 1.28 & 2.27 & 1.6 \\
\hline
\end{tabular}


The respondents also ranked their perceived efficiency and effectiveness in teaching and performing extracurricular activities wearing each dress. Wilcoxon Signed Rank test results showed that efficiency and productivity in performing extracurricular activities $(\mathrm{p}<0.05, \mathrm{p}=0.000)$ and teaching $(\mathrm{p}<0.05, \mathrm{p}=0.027)$ were significantly different proving that efficiency and productivity is significantly higher when they were in casual dress compared to Saree.

Vulnerability to risks and the tendency to face accidents were recorded considering both dresses separately. They ranked it in a five-point Likert scale (1-very high and 5- very low). Wilcoxon Signed Rank test was used to find out if there was a significant difference between the responses. Results showed that the difference was significant $(\mathrm{p}<0.005)$ and many respondents found Saree as a dress which was vulnerable to risks compared to casual dress. Mean value for the vulnerability to risks wearing casual dress was 4.21 whereas the mean value for vulnerability to risks wearing Saree was reported as 2.04. They were also asked if they have faced any difficulties/ accidents because of dress. Thirty three percent of the participants have answered saying yes, while $62 \%$ said no. The respondents who answered "yes" were also asked to categorize the type of difficulty/accident that they have faced. $20 \%$ of them have fallen entangling dress somewhere, while ten of them have fallen standing on their own dress, and three reported road accidents and other difficulties. Moreover, the respondents ranked their satisfaction about the job they do and about the dress they wear at work. They ranked this in a five-point scale (1highly dissatisfied, 2- dissatisfied, 3- neither satisfied nor dissatisfied, 4- satisfied and 5- highly satisfied). They were comparatively satisfied with the job (mean=3.75) than the dress (mean=3.49).

Tests were performed to understand relationships between different variables. Spearman Correlation was taken into consideration to understand association between variables. Accordingly, it was revealed that the age and the perceived comfort for Saree showed a statistically significant positive correlation $\left(\mathrm{r}_{\mathrm{s}}=0.233\right.$, $\mathrm{p}<0.05$ ), while the age and the perceived comfort for casual dresses have negative correlation $\left(\mathrm{r}_{\mathrm{s}}=-0.145\right)$. Similar relationship was observed between years of experiences and perceived comfort for both the dresses. Working experiences and the perceived comfort for Saree have a statistically significant positive correlation $\left(r_{s}=0.281, p<0.05\right)$, while the working experience and the perceived comfort for casual dresses have statistically significant negative correlation $\left(r_{s}=-0.294\right.$, $\mathrm{p}<0.05)$.

The respondents were given five statements to rank their agreement in a five-point scale in order to understand the relationship between the dress and the job 
performances (1- not at all, 2- no, 3- undecided, 4-yes and 5- yes, certainly). According to the results, mean value of the computed single variable was 17.47(out of 25). This shows that more than $50 \%$ of participants have stated that the dress they wear has an influence on their job performances.

\section{Qualitative Results}

Interviews were conducted with 15 teachers/teacher educators. Though the rules and regulations do not particularly ask Sri Lankan school teachers to wear Saree, they seem to wear them willingly. If the quantitative results are brought in line with the results of the interview, it is clearly understood that this is not pure willingness, as some of the interviewees said that they wear it for the sake of wearing, as they fear lack of respect in absence of Saree. Interviews showed that teachers find Saree a beautiful and socially reputed dress though it is a complex dress which is difficult to wear as a regular wear, especially for a teacher to perform her tasks. Saree also seems to be a dress which is vulnerable to accidents as revealed by the quantitative findings. Below mentioned are some selected quotes derived from the interviews.

"I usually go to school with my husband by motor bike. One day, the fall of my Saree got entangled in one of the wheels of the bike and my husband could not stop the bike immediately. So, I was thrown down. I got injured and a severe damage was caused to my leg."

(Interviewee 6, Age 53)

"Since there are few Physical Education teachers in my school, I was asked to teach Health and Physical Education to grade 9 and 10 students. Though the Health Science section can be done inside the classroom, introducing games like volleyball, netball and track and field events, going outside the classroom is vital, as the lessons include rules and regulations, skills of each games etc. Since I have done sports in my school time and at the teacher training college afterwards, I could have taught them in an interesting way. One day, I tried this going outside and taking a volleyball which put me in a really uncomfortable situation, because movements were really difficult to perform correctly wearing Saree. Since then I teach everything on the blackboard"

(Interviewee 10, Age 27)

Interviewee 10 was cross-questioned to know if she was allowed to wear a sportswear when doing practical sessions. According to the interviewee, Physical Education teachers are allowed to wear such attires, but she was not willing to do as her all the other classes are not related to physical education, because her main subject was English, so that she found it not practical at all. This can be considered as one of the worst instances teachers may face due to the complexity of the dress. 
Furthermore, it was also revealed by the interviewees that many female Physical Education teachers do not wear sportswear at school either, except during the days the school gets ready for the annual sports meet or any other competitions to be held.

Questions were also asked about the cost of the dress and the ways of handling the dress. All the interviewees agreed that affording Sarees are expensive compared to casual apparels. One particular comment highlighted this:

"The average cost of a Saree ranges from 8.04 USD to 32.14 USD (1USD= 186.68 Sri Lankan Rupees). Then, a jacket for the Saree should be sewed, which will cost nearly 2.68 USD up to 4.29 USD including the cost of lining material for the jacket piece and the charge of the tailor. An underskirt should be worn to match with the colour of the Saree, which will cost nearly 1.61 USD. A high heeled shoes should also be worn as Saree is a long dress. Normally, a teacher may possess 30 Sarees or more than that. Since Sarees are not worn for any other purpose than for work, this is an extra expense" (Interviewee 15, Age 29)

Considering this comment, it is fair to say that affording a Saree is really expensive compared to the average income of these teachers, which is around 213.45 USD per month. Nevertheless, the cost for the shoes can vary. Three respondents of the interview said that they do not wear heels with Saree, as they causes back pains and other inconveniences. In contrast, most of others said that they have to wear heels even with reluctance to avoid difficulties, as Saree is really lengthy.

Supporting the statistical analysis of quantitative data, all the interviewees believed that Saree takes a lot of time when getting ready for work. Each of the interviewees were asked the approximate time that they take to iron a Saree and to get it dressed.

The average time spent for ironing was calculated as 13 minutes and the average time spent for dressing was calculated as 14 minutes. It was also revealed by the respondents that, depending on the fabric and experience in wearing Saree, the time taken for ironing and dressing may differ, while ironing may not be needed for silk Sarees, ironing is strictly needed, and takes more time for handloom Sarees. Moreover, people who are more experienced in wearing Saree may be quicker in getting dressed than naive. Some of the results of the interviews were qualitatively analyzed using thematic analysis. 
Table 5: Coding frame work for the results of the interviews of Sri Lankan sample

\begin{tabular}{|c|c|c|c|}
\hline Participant comment & $\begin{array}{l}\text { Initial } \\
\text { coding }\end{array}$ & Categories & Themes \\
\hline $\begin{array}{l}\text { Saree is not a convenient dress } \\
\text { (sariyaapahasui). There } \\
\text { should be a simple and more } \\
\text { suitable dress for teachers than } \\
\text { this. But it also should be } \\
\text { decent (Interviewee 1, Age } \\
\text { 31). }\end{array}$ & $\begin{array}{l}\text { Complex dress } \\
\text { but simplicity } \\
\text { and decency are } \\
\text { concerns. }\end{array}$ & $\begin{array}{l}\text { Appearance } \\
\text { and handling }\end{array}$ & $\begin{array}{l}\text { Good } \\
\text { appearance } \\
\text { and difficult to } \\
\text { handle }\end{array}$ \\
\hline $\begin{array}{l}\text { I am extremely satisfied with } \\
\text { my dress. There is no any } \\
\text { other suitable dress for } \\
\text { teachers than Saree } \\
\text { (Interviewee 2, Age 49). }\end{array}$ & $\begin{array}{l}\text { Satisfied. Very } \\
\text { suitable. }\end{array}$ & & \\
\hline $\begin{array}{l}\text { Saree is good. But sometimes } \\
\text { really uncomfortable So, it is } \\
\text { better to have any other dress, } \\
\text { which would be decent and } \\
\text { covers the body properly } \\
\text { (Interviewee } 3 \text {, Age 29). }\end{array}$ & $\begin{array}{l}\text { Good but } \\
\text { difficult. Decent } \\
\text { dress is needed. }\end{array}$ & & \\
\hline $\begin{array}{l}\text { Even though Saree supports to } \\
\text { maintain respect, distance, } \\
\text { personality the difficulties that } \\
\text { are faced when worn daily are } \\
\text { high (Interviewee } 4 \text {, Age } 38 \text { ). } \\
\text { It is difficult to do teaching } \\
\text { wearing a complex dress like }\end{array}$ & $\begin{array}{l}\text { Maintain } \\
\text { respect and } \\
\text { personality. } \\
\text { Difficulties are } \\
\text { noteworthy. } \\
\text { Dress is difficult } \\
\text { wear }\end{array}$ & $\begin{array}{l}\text { Reputation and } \\
\text { handling }\end{array}$ & $\begin{array}{l}\text { Reputed and } \\
\text { difficult }\end{array}$ \\
\hline $\begin{array}{l}\text { Saree. Faced an accident: Fell } \\
\text { down entangling Osari in the } \\
\text { body (Interviewee } 5 \text {, Age } 42 \text { ). }\end{array}$ & & & \\
\hline $\begin{array}{l}\text { Wearing Saree is pleasant to } \\
\text { others. But,when traveling to } \\
\text { work from a faraway place, } \\
\text { this dress is really }\end{array}$ & $\begin{array}{l}\text { Pleasant to } \\
\text { others. Difficult } \\
\text { to travel } \\
\text { wearing Saree. }\end{array}$ & & $\begin{array}{l}\text { Pleasant to } \\
\text { others but } \\
\text { inconvenient }\end{array}$ \\
\hline $\begin{array}{l}\text { inconvenient. Because it } \\
\text { wastes time, energy and } \\
\text { money. Even some pregnant } \\
\text { ladies wear Saree during this } \\
\text { period which is an } \\
\text { inappropriate thing. } \\
\text { (Interviewee 6, Age 53) }\end{array}$ & & & \\
\hline $\begin{array}{l}\text { Though Saree has been given } \\
\text { due respect in the society, it is } \\
\text { an uncomfortable dress which } \\
\text { even reveals body. Moreover, } \\
\text { when wearing it in sunny days, }\end{array}$ & $\begin{array}{l}\text { Uncomfortable } \\
\text { and reveals } \\
\text { body }\end{array}$ & Body exposure & $\begin{array}{l}\text { Reveals } \\
\text { body }\end{array}$ \\
\hline
\end{tabular}


since the jacket is tight, sweating is really inconvenient (Interviewee 7 , Age 26).

Too much time is spent for Saree, whether it be for washing, drying, folding, ironing or even putting it on (Interviewee 8, Age 42)

Considering teacher's salary affording Sarees is very difficult. It would be better if we had freedom like in international schools at least to wear another dress when doing sports or any activities outside the classroom (Interviewee 9, Age 45).

Saree and Osari reduce the efficiency. The cost is too high for this dress and difficult to afford with the low salary of a teacher(Interviewee 10, Age 26)

Though Saree is found to be an uncomfortable dress it is necessary to keep the reputation from the society

(Interviewee 11, Age 35)

Though Saree promotes professionalism and can be used to earn respect, considering its comfort and what it is used for, Saree is not a suitable dress (Interviewee 12, Age 51).

Though Saree gives professional importance on the other hand it limits physical movements and causes reduced efficiency(Interviewee

13,Age 30)

In terms of efficiency, casual dress is better at school. In terms of social acceptance, Saree is the best(Interviewee 14, Age27).
Takes too much Time of time

Time

consuming

Not affordable

Affordability

Cost is high, difficult to afford

Low efficiency

Reduces

efficiency.

Costly

Uncomfortable.

Keeps

reputation

Promotes

professionalism.

Not suitable

Promotes

professionalism.

Reduces

efficiency

High acceptance

low efficiency

Efficiency and satisfaction
Uncomfortable and low

Professionalism efficiency and handling but professional and highly accepted 
Highly dissatisfied about the dress. It is not practical at all to have it as a dress code.
Causes lots of physical

Dissatisfied, Dissatisfied issues(Interviewee 15, Age 29)

Not practical.

Uncomfortable

\section{Discussion}

The first objective of the study was to understand the factors that determine official dress code. Secondary data from books and articles was incorporated to achieve this objective. The evolution of female clothing in Sri Lanka helped to understand, that more concern was given to the nationalism in deciding the suitable workplace attire for women in Sri Lanka. Especially, it was made clear based on the literature, that there are no evidences to prove that Sri Lankan most popular female dress code Saree was decided based on any logical or rational background. Furthermore, Sri Lankan culture has selected Saree as the most decent dress for women as many working women wear Saree to their work place. The second objective of the study was to determine sociological, psychological, economic and safety outcomes of an official dress to investigate the effects of a dress on the job performances of the wearer. The most preferred dress of majority of Sri Lankan teachers was casual dress at school, while their current dress was Saree. Though they are not obliged by law to wear Sarees at school, they do not try to wear their preferred casual dresses. This shows people's strong motivation to conform to the existing beliefs and practices, as well as the prominent role that the culture plays in decision making (Oliveria, 2007), as this dress norm is a creation of the culture itself: not enforced by law. This also shows that social reputation and the fear of being rejected from the society are prioritized over physical comfort, efficiency in terms of time and convenience in relation to dress (Kruglanski \& Webster, 1991; Thinada \& Rujirutana, 2008).

The difference between the comfort scores given for both dresses, was statistically significant $(\mathrm{p}<0.05)$ proving that casual dresses are more comfortable than Sarees. The majority of Sri Lankan teachers believed that the dress was not a barrier to communication. They agreed that the dress helps to show the society that they are teachers, but dress does not communicate authority. In response to the body exposure from the current dress, Sri Lankan teachers believed that their dress reveals certain extent of the body and they said that it was uncomfortable to them. This is due to the way a Saree is worn which necessarily reveals certain extent of the body (Jayasooriya, 2016).

It was revealed that the time taken for ironing, washing, dressing and walking 
was high when Saree was considered, while time was less and efficiency was high when casual dresses were considered. Family members, relatives, school administration, school community and the general public seem to be equally influential to decide the dress of Sri Lankan school teachers. Teachers believed that their efficiency and productivity in teaching and performing extracurricular activities were high when they are dressed casually compared to that of Saree. Teachers believed that Saree is vulnerable to risks, compared to casual wear. Thirty three percent of the respondent teachers had faced accidents/difficulties due to their current dress at school (Saree): this confirms that Saree is relatively risky dress as proven in the previous research conducted in India (Kumar et al., 2006; Yadav et al., 2016; Gupta et al., 2016). Teachers believed that their job performances were affected by the dress worn at work. This finding is in line with the findings of previous researches of some other countries (Kaser et al, 2009; Gutierrez \& Freese, 1999).

Moreover, the results also showed that economic concerns of the dress are also important. According to the results, one Saree costs $15 \%$ of the average salary of a teacher. Especially Saree is not a ready-made dress, so there are some other costs added even after buying a Saree. This shows that teachers spend quite a lot of money for this dress and since Saree can hardly be used other than at work, it is completely an additional cost. Hence, these findings prove McPherson's (1997) and Sharkey's (2000) idea of cost savings for employees if they are to wear casual dresses. Furthermore, as per data, teachers comparatively spend more time to handle and maintain Saree. It also seems that this dress restricts 'activeness' of a teacher. This can be understood as one of the critical findings of the research because minimized dynamic nature of teaching directly affects the quality of the teaching learning process. Given what the teachers have stated, their teaching would be more efficient and more productive if they could wear casual dresses.

Furthermore, thematic analysis of the qualitative data, provides an in-depth understanding about the results of the study. Affirming with the statistics, it reveals that Saree is not a comfortable dress. Respondents' preference for a comfortable dress (casual wear) also has been revealed clearly. The respondents' acknowledgement of the fact that Saree derive respect from the society and adds values to the personality shows their understanding about the role, social and event schemas (Vinney, 2019) and symbolically assigned meanings (Kaiser, 1983) to the profession of teaching in the Sri Lankan society. Unspoken difficulties in handling Sarees and lack of affordability compared to the monthly salary of teachers were also further confirmed through the analysis. Nevertheless, 
many responses of the participants clearly showed their fear for deviation from accepted dress norms, to which the reason can be the fear of rejection from the society (Bernheim, 1994). The analysis has generated few more negative themes: dissatisfaction, lack of comfort, low efficiency, high cost/ lack of affordability, time consuming, inconvenience, difficulty to handle and reveals body. Few positive themes too were derived from the analysis: good appearance, reputed, pleasant to others and professional. However, the results of the thematic analysis confirms the results of the quantitative study while giving deeper understanding about quantitative findings.

\section{Conclusion}

Saree has been established as the most suitable dress for women in general and for the working women based on cultural grounds. It is recognized as a decent and culturally reputed dress that helps to portrait teacher personality to the society. Nevertheless, the most preferred dress of teachers was casual dress, while their current dress was Saree. Teachers find Saree, a relatively uncomfortable dress, which takes notable time and effort to handle. They also find it expensive and difficult to afford and maintain. It is also evident that this dress might make the wearer vulnerable to accidents. Moreover, it is manifest that Saree exposes certain parts of the body, which seems uncomfortable for teachers. Female school teachers' efficiency and effectiveness of teaching and performing extracurricular activities are supposed to be higher, if they are given the opportunity to dress casually. Thus, Sri Lankan female teachers' dress should be changed in favour of the dynamic role that teachers assume. Doing so would enhance the efficiency and productivity of the duties they perform, while ensuring their self-satisfaction and safety, bringing them some savings in terms of time and money.

\section{Limitations of the Study}

The present study was based on the perceptions. The results would be more accurate and interesting if job performances could have been measured for both the dresses separately for an ideal comparison. Moreover, sample size was limited due to time, geographical and financial constraints. Results would have been generalized with a larger sample. 


\section{Recommendations}

It is recommended that Sri Lankan female teachers' dress should be changed in favour of the dynamic role of the teacher to enhance the efficiency and productivity, which on the other hand will ensure their self-satisfaction, safety and also bring economic benefits in terms of saving money and time. Moreover, the findings of this study encourages researching dress norms of other occupations in relation to job performances with special reference to the research methodologies and findings of researches conducted worldwide with the purpose of seeking recommendations to enhance working conditions. The present study examined perceptions to draw most of the conclusions. Future research in this discipline with more empirical data are encouraged to widen the understanding which will be a benefit for policy formulations for employees in Sri Lanka. The responsible authorities could be better convinced to change policies based on such research findings.

\section{Acknowledgements}

The authors thank Dr. Yasith Mathangasinghe, for critically reviewing the manuscript and Grave Valentin for continuous encouragements and careful proof reading.

\section{Declaration of Conflicting Interests}

The authors declared no potential conflicts of interest with respect to the research, authorship, and publication of this article.

\section{References}

Alicke, M. D., Smith, R. H., \& Klotz, M. L. (1986). Judgments of Physical Attractiveness: The role of faces and bodies. Personality and Social Psychology Bulletin. 12,381-389.

American Psychological Association (n.d.). Self- concept. In APA dictionary of psychology. Retrieved on 18 September 2020, from https://dictionary.apa.org/self-concept

Bellezza, S., Gino, F., \&Keinan, A. (2013). The red sneakers effect: Inferring status and competence from signals of nonconformity. Journal of consumer research, 41(1), 35-54.

Bernheim, B.D. (1994)."A Theory of Conformity," Journal of Political Economy 102, (5), $841-877$. 
Bhui, K., Khatib, Y., Viner, R., Klineberg, E., Clark, C., Head, J., \&Stansfelf, S.A. (2008). Cultural identity, clothing and common mental disorder: a prospective school-based study of white British and Bangladeshi adolescents. Journal of Epidemiology and Community Health, 62(5), 435-441.

Bishop, P. A., Balilonis, G., Davis, J. K., \& Zhang, Y. (2013) Ergonomics and Comfort in Protective and Sport Clothing. A Brief Review. J Ergonomics, S2(5). doi:10.4172/2165-7556.S2-005

Cialdini, R. B., \& Goldstein., N.J. (2004). Social Influence: Compliance and Conformity. Annual Review of Psychology, 55(1974), 591-621.

Fernando, W.T.A.L. (2007, January 17). National Dress Suits Our Country, Climate and Culture, Daily newsonline. https://archives.dailynews.1k/2007/01/17/fea02.asp

Furnham, A., Chan, P.S., \& Wilson, E. (2014). What to wear? The Influence of Attire on the Perceived Professionalism of dentists and lawyers, Journal of Applied Social Psychology, 43(9), 1838-1850.

Franz,T.M., \& Norton, S.D. (2001). Investigating Business Casual Dress Policies: Questionnaire Development and Exploratory Research. Applied HRM Research, 6(2), 79-94

Gentile, E. \&Imberman, S.A. (2010). Dressed for. Success? The effect of school uniform on student achievement and behavior. Journal of Urban Economics, 71(1), 1-17.

Guest, G., Namey, E., \& Chen, M. (2020). A simple method to assess and report thematic saturation in qualitative research. PLOS ONE. https://doi.org/10.1371/journal.pone.0232076

Gupta, V., Kumar, A., Gupta, P., Singh, S.P., Singh, S.P., Singh, V., Srivastava, S., Verma,S., Singh, R.C., \& Singh, M. (2016). Pattern of two wheeler road traffic accidents in rural setting: a retrospective study. International Surgery Journal, $3(2), 521-525$.

Gutierrez, T.,\&Freese, R. J. (1999). Dress-down days: Benefit or burden?. CPA Journal, 69(4), 32-37.

Hewavissenti, A. (2014, June 15). The dress and adornment in ancient Sri Lanka.

Sunday Observer. www.sundayobserver.lk/2014/06/15/imp03.asp

Huitt, W., (2004). Maslow's hierarchy of needs. Educational psychology interactive. Valdosta, GA: Valdosta State University.

Hunt, S. A., \& Miller, K. A. (1997). The discourse of dress and appearance: Identity talk and a rhetoric of review. Symbolic Interaction, 20(1), 69-82. 
Hughes, S. M. (2002). The effect of casual dress on performance in the workplace. Undergraduate Research Journal for the Human Sciences. http://www.kon.org/urc/maloney.html

Imo, B. (2013). Adoption of the Kenya National dress as a basic for developing a decision-making model for the local industry: A case of Nairobi, Kenya [Doctoral dissertation, Kenyatta University].

https://pdfs.semanticscholar.org/6a4a/65c072a1ade637e210bea6638605ac4ad1fa. pdf

Jackson, H. O., \& O'Neal, G. S. (1994). Dress and appearance responses to perceptions of aging. Clothing and Textiles Research Journal, 12(4), 8-15.

Jayasooriya, U.G.L.B. (2016). Clothing in Sri Lanka: Cultural Conformity and Contradictory Rejection of Women's Individuality. Proceedings of the International Research Symposium on Innovation for Sustainability, Sri Lanka, 3(2), 327-332.

Jayasooriya, U.G.L.B., De Silva, s., \& Wanigasundara, W.A.D.P., (2020). Dress Codes of Female Employees and their Job Performances in Sri Lanka. Journal of Humanities and Social Sciences. 3(1), 55-67.

Jayawardena, J. (2002). Cultural Construction of the 'Sinhala women' and women's lives in Post-independence Sri Lanka [Doctoral dissertation, University of York, Centre of women's studies]. http://etheses.whiterose.ac.uk/14014/1/288244.pdf Jayawardena, K., \& De Alwis, M. (1996). Embodied violence: Communalising women's sexuality in South Asia. Reproductive Health Matters, 4(8), 162-166.

Kaiser, S. B. (1983). Toward a contextual social psychology of clothing: A synthesis of symbolic interactionist and cognitive theoretical perspectives. Clothing and Textiles Research Journal, 2(1), 1-9.

Kaser, M., Bugle, L.W., \& Jackson, E.(2009). "Dress code debate." Nursing management, 40(1), 33-38.

Kruglanski, A.W., \& Webster, D.M. (1991). Group Members Reactions to Opinion DFeviants and Condormists at Varying Degrees of Proximity to Decision Deadline and of Environmental Noise. Journal of Personality and Social Psychology, 61(2), 212-225.

Kumar, T.S.M.,Yoganarasimha, T.K.K., \& Kumar, G.P.(2006). Profile of unnatural deaths in Manipal, Southern India 1994-2004. Journal of Clinical Forensic Medicine,13(3),117-120.

McCall, G. J., \& Simmons, J. L. (1966). Identities and interactions. psycnet.apa.org

McPherson, W. (1997). "Dressing down" in the business communication curriculum. Business Communication Quarterly, 60(1), 134-146. 
Melchior, M.R., \& Skov, L. (2008). Research Approaches to the Study of Dress and Fashion. Creative Encounters.

Ministry of Education. (2012). Circular number 2012/37: Guruwarunge Sadacharathmaka Hasirima Pilibada Achara Dharma Paddathiya ha Podu nithi malawa.

http://www.moe.gov.lk/english/index.php?option=com_circular\&view=circular\&i $\mathrm{d}=119 \&$ Itemid $=920$

Ministry of Education. (2017). School Census Report.

http://www.statistics.gov.lk/education/School\%20Census\%20Report 2017.pdf

Ministry of Education. (2018). Circular number 21/2018: Introduction of Appropriate Dress to Pregnant School Teachers.

http://moe.gov.lk/index.php?option=com_circular\&view=circular\&cid=1457\&Ite mid=151\&lang=en

Nath, V., Bach, S., \& Lockwood, G. (2016). Dress codes and appearance norms at work: Body supplements, body modifications and aesthetic labour. School of Management and Business King's college www.acas.org.uk/researchpaper

Nickson, D., Warhurst, C., \& Dutton, E. (2005). The importance of attitude and appearance in the service encounter in retail and hospitality. Managing Service Quality: An International Journal, 15(2),195-208. https://doi.org/10.1108/09604520510585370

Roach-Higgins, E., \& Ellen, J. B. M. (1995). Dress and identity. Fairchild Publications.

Rosenfeld, L.B., \& Plax, T.G. (1997). Clothing as Communication, Journal of Communication, 27(2), 24-31.

Sampson, E.C. (2016). Teachers' Perceptions of the Effect of their Attire on Middle-school Students' Behaviour and Learning [Doctoral dissertation, Walden University] Walden University Scholar Works. https://scholarworks.waldenu.edu/dissertations/2078/

Schliesinger, J. (2014). Sexuality in Asia: From South Asia to Japan. White Elephant Press

Sharkey, M.A. (2000). A study to determine how casual dress in the workplace affect employee morale \& productivity. [Doctoral dissertation, Rowan University]. Rowan Digital Works https://rdw.rowan.edu/cgi/viewcontent.cgi?article=2745\&context=etd Singh, A., \& Kenneth, S.R. (2014). A Study on Workplace Attire in Indian Corporate. International Journal of Engineering Technology, Management and Applied Sciences, 2(4), 37-47. 
Slepian, M.L.(2015). The Cognitive Consequences of Formal Clothing, Social Psychological and Personality Science, 6(,6), 661-668.

Social actions. (2020,10 September). In Wikipedia. https://en.wikipedia.org/wiki/Social_actions

Thinada, P., \& Rujirutana, M.(2008). Psychological antecedents of career women's fashion clothing conformity. Journal of Fashion Marketing and Management: An International Journal, 12(4), 438-455, https://doi.org/10.1108/13612020810906119

Vinney, C. (2019). What is a Schema in Psychology? Definition and examples. ThoughtCo. https://www.thoughtco.com/schema-definition-.

Wickramarachchi, P. (2003).A Study on Social meaning of "Clothes" in Sri Lanka. http://www.academia.edu/10010445/A_study_on_social_meaning_of_clothes_ in_Sri_Lanka

Wickramasinghe, M. (1935). Dress and Ornament in Ancient Ceylon. Mount Press. Wickramasinghe, N. (2003).Dressing the colonized body: Politics, Clothing and Identity in colonial Sri Lanka. Orient Longman.

Yadav, A., Sharma, N., Kumar, M., \& Gupta, S.K. (2016). A case of Ligature Strangulation in an Agriculture Accidents with unusual Autopsy Findings, $A R C$ Journal of Forensic Science, 1(3), 21-24.

Zoysa, A.D. (2015), "Gendering the Colonized and Dressing the De Colonized Female Body" Nivedini Journal of Gender Studies,20,1-37. http://www.wercsl.org/wp-content/uploads/2016/03/Nivedini-Journal-onGender-Studies-2014-2015.pdf 